Research, Society and Development, v. 9, n. 10, e2489108512, 2020

(CC BY 4.0) | ISSN 2525-3409 | DOI: http://dx.doi.org/10.33448/rsd-v9i10.8512

\title{
A importância estratégica do Compliance Tributário nas empresas
}

The strategic importance of Tax Compliance in companies

La importância estratégica del Cumplimiento Tributario em las empresas

Recebido: 15/09/2020 | Revisado: 19/09/2020 | Aceito: 23/09/2020 | Publicado: 25/09/2020

Walkyria Carvalho

ORCID: https://orcid.org/0000-0001-8914-274X

Faculdade de Ciências da Administração de Pernambuco, Brasil

E-mail: Walkyria_1@hotmail.com

José Luiz Alves

ORCID: https://orcid.org/0000-0003-2049-2084

Faculdade de Ciências da Administração de Pernambuco, Brasil

E-mail: luiz.alves@upe.br

\section{Resumo}

O presente artigo objetiva propor uma reflexão sobre a importância da adequação normativa de uma empresa na adoção de Programas de Compliance, com vistas a se auferir benefícios para a gestão, especialmente com relação aos impactos dos tributos nas receitas e redução de riscos através da elisão fiscal, objetivo mais nítido do planejamento tributário. Através do método de revisão bibliográfica, conferimos a importância do presente estudo às práticas empresariais proativas, cujos resultados têm sido propositivos para a administração de empresas. Os resultados obtidos com esta pesquisa se situam no campo positivo e esperado de prospecção de facilidades para as empresas, o que se observou através da adoção de programas de Compliance automaticamente revertidos em benefícios para a companhia, refletindo, por conseguinte, na gestão e na sua relação com seus colaboradores e stakeholders, que usufruem, indiretamente, da credibilidade da empresa planejada. Através do presente estudo conclui-se que as empresas que adotam o Compliance Tributário têm menos custos, maiores lucros, maior celeridade laboral e um alcance de resultados diferenciado, o que as torna verdadeiros modelos de gestão, consolidando a sua marca como referência em credibilidade. O Compliance, sem qualquer dúvida, conforme se destaca nos resultados desta pesquisa, tem sido apontado com a ferramenta mais adequada para o alcance dos objetivos de um bom planejamento tributário e estes benefícios alcançam resultados, também, na redução 
de riscos para a empresa, diminuição ou eliminação de seus gastos extras e dos impactos tributários na gestão.

Palavras-chave: Compliance tributário; Planejamento empresarial; Elisão fiscal.

\begin{abstract}
The purpose of this article is to propose a reflection on the importance of the normative adequacy of a company in the adoption of Compliance Programs, with a view to obtaining benefits for management, especially in relation to the impacts of taxes on revenues and risk reduction through the tax avoidance, the clearest objective of tax planning. Through the bibliographic review method, we confer the importance of this study to proactive business practices, whose results have been propositional for business administration. The results obtained with this research are in the positive and expected field of prospecting for facilities for companies, which was observed through the adoption of Compliance programs automatically reverted to benefits for the company, reflecting, therefore, in management and its relationship with its employees and stakeholders, who indirectly enjoy the credibility of the planned company. Through this study it is concluded that the companies that adopt Tax Compliance have less costs, higher profits, greater labor speed and a differentiated results range, which makes them true management models, consolidating their brand as a reference in credibility. Compliance, without any doubt, as highlighted in the results of this research, has been identified as the most appropriate tool for achieving the objectives of good tax planning and these benefits also achieve results in reducing risks for the company, reducing or eliminating your extra expenses and tax impacts on management.
\end{abstract}

Keywords: Tax compliance; Business planning; Tax avoidance.

\title{
Resumen
}

El propósito de este artículo es proponer una reflexión sobre la importancia de la adecuación normativa de una empresa en la adopción de Programas de Cumplimiento, con miras a obtener beneficios para la gestión, especialmente en relación a los impactos de los impuestos sobre la recaudación y la reducción de riesgos a través de la la elusión fiscal, el objetivo más claro de la planificación fiscal. A través del método de revisión bibliográfica, atribuimos la importancia de este estudio a las prácticas empresariales proactivas, cuyos resultados han sido propositivos para la administración de empresas. Los resultados obtenidos con esta investigación se encuentran en el campo positivo y esperado de la prospección de instalaciones para empresas, lo cual se observó a través de la adopción de programas de 
Compliance revertidos automáticamente en beneficios para la empresa, reflejándose, por tanto, en la gestión y su relación con sus empleados y grupos de interés, quienes indirectamente gozan de la credibilidad de la empresa planificada. A través de este estudio se concluye que las empresas que adoptan el Cumplimiento Fiscal tienen menores costos, mayores ganancias, mayor rapidez laboral y un rango de resultados diferenciado, lo que las convierte en verdaderos modelos de gestión, consolidando su marca como referencia en credibilidad. El cumplimiento, sin duda alguna, como se destaca en los resultados de esta investigación, ha sido identificado como la herramienta más adecuada para lograr los objetivos de una buena planificación fiscal y estos beneficios también logran resultados en la reducción de riesgos para la empresa, reduciendo o eliminar sus gastos adicionales y los impactos fiscales en la gestión.

Palabras clave: Cumplimiento tributário; Planificación empresarial; Evasión de impuestos.

\section{Introdução}

A atividade empresarial no Brasil é uma reconhecida força financeira, que move a roldana da economia nacional com pulsos fortes. Por se tratar de um país composto, em sua origem, de uma essência permanentemente trabalhadora, tanto em decorrência dos movimentos migratórios, a exemplo dos italianos e alemães que se sacrificaram para construir a economia deste país, como pelo infeliz capítulo da escravidão no Brasil, a realidade é que o povo brasileiro edificou, dia a dia, com muito sacrifício, o passado de uma história de luta que serviu de respaldo a todas as gerações presentes, muitas das quais ainda fruidoras dos frutos auferidos nesse combate. Muito se deve, principalmente, ao espírito de luta que o brasileiro possui, tanto em sua história de existência, quanto das superações às mazelas do desequilíbrio financeiro do país.

Para manter as conquistas dos trabalhadores, muitos são os que optaram por empreender, criar suas marcas, suas empresas, realizar seus negócios no Brasil. No entanto, sabe-se, também, que embora a vontade de empreender seja influente em boa parte dos negócios gerados no país, muitos são os percalços vivenciados pelos empreendedores, a exemplo do desconhecimento de noções de administração, ou ausência de familiaridade acerca da atividade empreendida, suas necessidades, localização, público, contabilidade, ajustes financeiros, e, por dados motivos, muitas empresas fecham suas portas em curto espaço de tempo. 
Research, Society and Development, v. 9, n. 10, e2489108512, 2020

(CC BY 4.0) | ISSN 2525-3409 | DOI: http://dx.doi.org/10.33448/rsd-v9i10.8512

O que, muitas vezes, estagna o pensamento gerencial nas empresas é a centralização dos poderes do gestor, principalmente quando ele está no comando desde a sua criação. Tratase de algo já institucionalizado no país, uma vez que muitos são os gestores que fortemente acreditam que, por conhecerem profundamente seu empreendimento, podem navegar entre as diferentes áreas de atuação, gerenciando, também, o trabalho desenvolvido em cada uma delas, como se especialista fosse. Nesse quadro, por exemplo, muitos são os administradores que fazem as contas do seu negócio porque não contratam contadores, ou pagam seus tributos erroneamente por não contratarem advogados para essa orientação. Muitos também são os gestores que preferem o antigo de porta em porta, mas não contratam marketeers ou publicitários e isso, na era digital, é uma pré-morte empresarial.

À parte dos prejuízos de marketing ou publicidade na área de comunicação empresarial, o comportamento do gestor centralizador enseja uma lacuna quase imperdoável na gestão de qualidade, uma vez que abre precedente na empresa para que uma porta se escancare e as mazelas da má gestão ali estacionem. Trata-se de uma economia de recursos com revestimento de tragédia anunciada, pois a empresa que não investe na sua própria proteção tende a ruir vertiginosa e lentamente, de maneira que até a recuperação judicial, muitas vezes, não tem capacidade de sustentar por muito tempo.

Não obstante haver-se por notório o risco de gerir uma empresa sem atendimento normativo, a perda financeira gerada pela ausência dessa atenção, aliada a uma perda ainda maior, referente à da credibilidade na imagem da marca, a gestão sem Compliance torna a administração da empresa, em algumas das vezes, temerária, desacreditada e sem o esteio da força sobre o seu próprio capital, que se perde em meio ao descontrole sobre a própria estrutura. O comportamento fiscal de uma empresa geralmente tem sua responsabilidade atribuída ao cenário legislativo em que se comporta a empresa em dado momento (Quentin, 2019).

Analisando-se o perfil das empresas que não lograram êxito na continuidade de suas atividades, observa-se que o elemento comum entre muitas delas é a instabilidade gerencial em torno dos encargos gerados por lei, especialmente com relação ao impacto tributário que todas elas sofrem com seus compromissos fiscais. A ausência de planejamento gerencial, seja através dos procedimentos adotados para sua administração, seja por decorrência dos pagamentos de haveres tributários, trabalhistas, fiscais e financeiros, gera uma instabilidade nas contas e um endividamento consequente que tornam impossível a manutenção da empresa no mercado. 
Research, Society and Development, v. 9, n. 10, e2489108512, 2020

(CC BY 4.0) | ISSN 2525-3409 | DOI: http://dx.doi.org/10.33448/rsd-v9i10.8512

Um planejamento tributário que consista na adoção de um Programa de Compliance na empresa reveste de boa-fé o gestor, que se ocupa em detalhar o perfil tributário e fiscal de seus negócios, esclarecendo sua estrutura organizacional em números e dados suficientes para um bom planejamento tributário. Nesse caso, abre-se a perspectiva de estudar com afinco as necessidades da empresa, com um olhar analítico e apurado sobre seus elementos formadores, sua estrutura organizacional, seu elemento pessoal e, evidentemente, sobre suas finanças. É com essa visão que se instala, no ano de 2000, o primeiro impacto do Compliance no Brasil.

O cenário gradativamente tende a piorar quando as medidas de risco tomadas em meio administrativo alcançam o equilíbrio tributário da empresa, retirando-lhe a estabilidade e a credibilidade de mercado. Diante dessa situação, muitas são as empresas que fecham precocemente suas portas, unicamente em decorrência de falta de gestão proativa. Essas empresas, portanto, com vistas a prorrogarem os pagamentos de suas obrigações tributárias, protelarem, também, as quitações de seus encargos e financiamentos, ou simplesmente não se programarem para os revestimentos passivos de suas finanças, aumentam consideravelmente suas contas a pagar, implicando em pagamentos de multas altíssimas, oportunizadas pela falta de atenção e cautela de prazos e valores, causando um decréscimo natural de seu próprio patrimônio e, consequentemente, o seu fim.

Por dado motivo, a adoção das medidas de Compliance tem sido uma grande aliada no fortalecimento das instituições, bem como na restauração de empresas, evitando o caos decorrente de corrupção, má gestão ou mesmo da ingenuidade de gestores ainda não preparados para o combate na manutenção de sua empresa no efervescente mercado empresarial brasileiro. Conforme preleciona a doutrina (Viol, 2015), “A priorização do cumprimento tributário não serve apenas como instrumento de mobilização de recursos, mas também influencia a eficiência e a equidade do sistema tributário". É necessário que se observe o cumprimento das leis tributárias no Brasil, mas também deve-se ater às muitas possibilidades que a empresa tem de, através da própria lei e dos meios que ela proporciona, realizar seu planejamento de maneira adequada e lícita.

"Não envolve, o Compliance, apenas a obediência a certos aspectos formais da legislação, mas um conjunto mais amplo de padrões, condutas éticas, absorção cultural e empoderamento dos empregados que encabeçam as suas principais medidas" (Oliveira, 2020). Desta feita, importa ressaltar que o Compliance não se torna, no Brasil, apenas uma adequação normativa simples e objetivamente aplicada. Trata-se, portanto, de uma nova concepção comportamental, através do qual, segundo o autor, a empresa para a ser "adjetivada". 
Através do presente estudo, pretende-se analisar a importância estratégica do Compliance Tributário nas empresas, traçando um caminho que se percorre desde sua definição, a adoção de medidas de Compliance Tributário no Brasil, tendo por objetivo primordial investigar a importância da implementação das medidas de adequação normativa empresarial para redução de riscos e danos na esfera Tributária.

Para alcançar os objetivos propostos, utilizou-se como recurso metodológico a revisão bibliográfica, realizada a partir da análise de literatura e artigos científicos publicados em meio físico ou eletrônico.

\section{Metodologia}

Para tratar do presente tema, optou-se por uma abordagem qualitativa, buscando-se aprofundar a questão pesquisada em torno de um determinado grupo que, neste caso, é referido como gestão empresarial de Compliance Tributário. (Gerhardt \& Silveira, 2009).

Para a abordagem qualitativa, em método descritivo, o objetivo em torno da descrição desse particular segmento e o fenômeno da gestão (Gil, 2008), realizado através de Compliance, foi auferido através de uma pesquisa bibliográfica, para se averiguar as múltiplas abordagens nos diferentes cenários em que o tema pudesse figurar.

O método qualitativo, portanto, é aquele em que "é importante a interpretação por parte do pesquisador com suas opiniões sobre o fenômeno em estudo" (Pereira, et al., 2018). É primordial que o pesquisador esteja disposto a discutir sua própria pesquisa, realizando, por conseguinte, a avaliação subjetiva proveniente de sua visão sobre o estudo realizado.

No intuito de apurar a base referencial do presente artigo, fez-se uso do método de Pesquisa Bibliográfica, através da qual buscou-se compreender e aprofundar, de forma indutiva, o entendimento acerca do objeto de estudo através das pesquisas realizadas em fontes secundárias, como livros e artigos científicos, em conformidade com intuito descritivo.

É ideal perceber que, para a produção de um artigo científico, em qualquer pesquisa, mas especificamente na bibliográfica, o autor pesquisa, lê, analisa e discute os resultados, se serve da base referencial bibliográfica, para, então, tecer suas considerações ao concluir seus estudos (Pereira, et al., 2018).

Para gerar robustez à presente pesquisa, utilizou-se de fontes entre artigos científicos de indexação de alta qualidade, entre diversas outras fontes de caráter bibliográfico. 


\section{Resultados e Discussão}

\subsection{Compliance como instrumento de regulação fiscal e planejamento tributário}

Compliance é um termo originário da Língua Inglesa, proveniente do verbo To Comply, que significa agir de acordo com o desejo de outrem ou em obediência a uma regra ${ }^{1}$ (Merriam-Webster, 2017). Em primeira linha, pode-se compreender Compliance como um conjunto de medidas de prevenção para adequação normativa de uma empresa, com intuito de atuar proativamente no alinhamento da empresa a regras, normas e leis em geral, gerando atenuação do impacto da incidência na lei e mantendo a empresa sempre adequada normativamente ao funcionamento legal.

Em uma perspectiva de solução de problemas, o Compliance pode ser considerado um conjunto de medidas capazes de identificar riscos, problemas ocorridos ou desvios na tomada de decisões, bem como propor a solução e, então, realinhar a empresa às normas legais, internas e externas. Trata de importante instrumento para a maximizar o cumprimento tributário, o que pode ser definido como "aproximar a arrecadação efetiva da arrecadação potencial, isto é, reduzir a brecha tributária para assegurar que a maior quantidade possível de recursos seja tributada de acordo com o marco legal do país" (Viol, 2015).

As ações internas de Compliance têm como objetivo fundamental a (re)adequação normativa da empresa, reduzindo as chances de ocorrências de demandas judiciais que possam, porventura, ser inauguradas contra a empresa. Esse trabalho preventivo, que demanda excelência advocatícia especializada no âmbito empresarial, opera um serviço de máxima valia na seara judiciária, uma vez que o volume de demandas judiciais cai vertiginosamente quando as empresas trabalham para reduzir seus custos, despesas e prejuízos. Trata-se de uma avaliação ética dos valores adotados no mundo corporativo. Importa ressaltar que "os valores e princípios éticos guiam a governança da organização para que a entidade jurídica não seja conduzida apenas de acordo com a vontade dos tomadores de decisão" (Sobreira Filho, et al., 2019). Trata, pois, o Compliance de aplicação de princípios éticos, para uma funcionalidade igualmente ética da máquina corporativa.

Em decorrência do aumento significativo de operações da Polícia Federal na apuração e autuação de empresários com acusações de gestão fraudulenta e desvio/apropriação de verbas públicas, o Compliance tem se tornado uma ferramenta essencial na busca pelo

\footnotetext{
${ }^{1}$ To act in agreement with another's wishes or in obedience to a rule.
} 
alinhamento normativo preventivo na empresa, de modo a evitar irregularidades dessa envergadura na própria condução da empresa. A percepção do Compliance como ferramenta de negociação da Pessoa Jurídica em acordos de leniência tem sido discutida, especialmente quando a empresa tem, contra si, severas acusações de fraudes, como evasão fiscal, o famoso "caixa dois" e as diversas modalidades de Money laundering.

Em discussão apartada, saliente-se que o Compliance também tem sido cogitado como meio de normativizar as ações do Estado, alinhando as gestões públicas aos seus verdadeiros escopos diante da sociedade. Nesse raciocínio, o Compliance Público se torna um "subsistema jurídico de integridade voltado para uma otimização da gestão de riscos, de políticas públicas e de transparência de informações" (Mudrovitsch \& Nóbrega, 2020).

É notório o conhecimento de que as empresas, normalmente, enfrentam uma série de burocracias e procedimentos regulatórios, que muitas vezes atrapalham sua gestão, unicamente por necessitarem de uma atenção apurada e especializada em cada um dos seus setores. Portanto, não há como discordar, quanto maior for a empresa, mais burocrática e minuciosa é sua adequação normativa, especialmente se a empresa for brasileira. Diante do volume de negociações que normalmente ocorrem, é necessário que a empresa tenha um bom Programa de Compliance, cujo esteio seja firmemente consolidado no seu planejamento tributário efetivo.

O comportamento adotado pela empresa, não apenas em seu planejamento, mas no efetivo cumprimento dos pagamentos idealizados vai dar surgimento a um padrão que pode, efetivamente, reduzir os gastos, diminuindo custos operacionais e, evidentemente, com os pagamentos de multas exorbitantes, tornando a empresa proativa no cumprimento das suas obrigações fiscais.

O planejamento tributário, no entanto, não se confunde com o gerenciamento de riscos tributários. O gerenciamento de risco "está relacionado com os riscos em processos e procedimentos voltados ao correto cálculo do tributo a ser recolhido, bem como com a satisfação das demais obrigações tributárias acessórias” (Miyoshi \& Nakao, 2012), o que destoa, imediatamente, da prevenção no planejamento.

Para que se possibilite a introdução do Compliance Tributário nestes escritos, é necessário ampliar a visão sobre o tema, conceituando o Compliance como um instrumento capaz de adequar normativamente a empresa e todo o seu patrimônio, material e pessoal, atuando através de medidas preventivas e acauteladoras sobre os fatos nela inseridos. As empresas brasileiras precisam ser bem avaliadas por empresas investidoras de outros países e isso ocorre através da adoção de um Programa de Compliance, uma vez que o background 
checking é necessário para se avaliar se no histórico de negociações das empresas existe um potencial risco para investimento. Em qualquer lugar do mundo, risco potencial existe em empresas que não cumprem com seus compromissos fiscais.

O programa de Compliance é responsável por manter a empresa alinhada com as normas internas e, principalmente, com as normas externas da estrutura corporativa, adequando sua atuação à legislação vigente, com vistas a reduzir, por ora, os riscos provenientes da não-observação no cumprimento das obrigações normativas. Através de um bom programa de Compliance, a empresa consegue reduzir consideravelmente o impacto das ocorrências que naturalmente são impostas às empresas e reduzir, de maneira satisfatória, os riscos e desvios nas condutas praticadas dentro da organização, buscando atendimento aos programas de integridade.

A adoção de medidas de Compliance não apenas torna a empresa digna de maior credibilidade no mercado corporativo, como também agrega valor à respectiva marca, uma vez que a empresa se mostra naturalmente preocupada com as regras, normas e leis anticorrupção do país. Com o advento da Lei $\mathrm{n}^{\mathrm{o}}$ 12.846/2013, conhecida como Lei Anticorrupção, muitas empresas procuraram meios de adequar suas atividades às normas, como forma de alinharem-se à citada lei e, por tal motivo, usufruírem das prerrogativas que lhes seriam, porventura, concedidas em caso de necessidade.

Desse modo, vê-se claramente a busca da empresa por excelência, mas também por regularidade, não apenas em seus próprios resultados, mas em todo o contexto de apuração de sua estrutura humana e material, considerando-se o fato de que tais medidas alcançam, necessariamente, a burocracia, os arquivamentos, a logística na empresa, o manuseios dos documentos, o gerenciamento de custos, pagamentos, haveres trabalhistas, problemas relacionados à estabilidade tributária, financeira e contábil da empresa, a manutenção, a propriedade, os direitos e obrigações e tudo o que orbita em torno da legislação municipal, estadual e federal, partindo-se do micro - normas internas, para o macro - legislação pertinente.

Um Programa de Compliance bem feito em uma empresa é praticamente uma radiografia bem executada de absolutamente tudo o que existe em suas dependências, com um planejamento excepcional no afã de se mitigar os riscos empresariais e, assim, garantir que esse trem volte para seus trilhos originais, o que não significa, necessariamente, dizer que um programa dessa envergadura é suficiente para eliminar todos os riscos de uma empresa, mas funciona muito bem como um programa de reeducação alimentar: uma vez eliminados os péssimos hábitos, adquirindo-se novos e melhores, fomentando-se uma análise bem feita dos 
problemas, dos riscos e projetando objetivos bem delineados, tudo de acordo com normas e regras bem definidas, a empresa (tanto quanto o reeducando alimentar) tende a agir de maneira mais correta, mais dinâmica, revitalizando-se, ganhando novos ares e vendo perspectivas mais positivas, quando os resultados chegam no cotidiano.

O ser humano possui dentro de si os sensos morais que delineiam sua conduta. Deste modo, muitos são os que agem corretamente porque desejam assim se conduzir, embora para a maioria tal "incentivo" seja proporcionado pela coerção da lei. Existe uma medida mediana que avalia a moralidade humana, como sendo o sentido do cumprimento dos deveres e das obrigações de cada ser humano, sendo tal contexto avaliado, também, sob uma perspectiva organizacional. As empresas, para cumprirem com suas obrigações fiscais, fazem uso de um senso de moralidade intrínseco, mas que, conforme se observa no ser humano, necessita, muitas vezes, de um instrumento de coerção. Ao optarem pela evasão fiscal, as empresas comprometem o alinhamento de suas atividades e sua vida financeira, uma vez que as multas pelo não cumprimento das obrigações tributárias tendem a ser excruciantes.

No caso do efetivo cumprimento das obrigações tributárias, em muito se deve às multas realmente exorbitantes e às fiscalizações que, a exemplo do ocorrido recentemente com uma famosa loja magazine de móveis e eletrodomésticos no Brasil, podem ser resultantes de longas e profícuas investigações em torno de sonegação fiscal. Nesse caso, a empresa deve mais de R \$ 133.000.000,00 em débitos fiscais, uma vez que a mesma recolhia o ICMS no ato da venda e não repassava ao Estado da Bahia (Redação, 2020).

De acordo com o Instituto Brasileiro de Planejamento Tributário (INPT, 2017), o índice de sonegação das empresas vem caindo e, na última data aferida, correspondia a 17\% do seu faturamento. A queda no índice de sonegação decorre de uma mudança de comportamentos no âmbito empresarial, uma vez que são constantemente criadas novas propostas éticas para a criação e manutenção da vida empresarial. A adoção de Programas de Integridade pelas empresas tem sido, também, responsável pela redução considerável de casos de sonegação nas empresas. Através de pequenas e pontuais atitudes, como treinamentos dos colaboradores, elaboração de estatutos e códigos de ética, manuais de política financeira, as empresas têm angariado um nível maior de credibilidade, o que pode ser facilmente identificado através das notícias acerca do bom desenvolvimento de suas atividades. Um excelente exemplo de planejamento e Compliance é a Hewlett-Packard, que realiza o Compliance de mais de 100 entidades legais, 30 entidades jurídicas não-operacionais, com apenas cerca de 30 colaboradores que apuram seus impostos e 3 pessoas dedicadas ao Compliance (Amaral, 2019). 
Para uma parte da doutrina (Viol, 2015), o desenvolvimento de um Plano Integrado de Cumprimento Tributário tem sido hábil no desenvolvimento de estratégias para que sejam colmatadas as faltas, reduzindo-se o impacto tributário, certamente através da redução do descumprimento. Segundo a autora, as administrações tributárias não têm colaborado com informações sobre a brecha de cumprimento fiscal pelas empresas, muito embora o Compliance tenha sido largamente utilizado para aferição destas informações. A autora atribui essa falta à complexidade do sistema tributário nacional e sua consequente ausência de transparência, o que promove, sem dúvidas, uma lacuna imensurável no sistema de informações que compromete a credibilidade de empresas no cenário internacional.

Ato inicial para a implementação do Compliance Tributário na empresa é a avaliação de uma política interna, que seja hábil na prevenção dos atos praticados no ambiente corporativo. Para tanto, elabora-se uma estrutura interna, com normas, regras de conduta ética, manuais práticos. Para que esse alinhamento seja perfeitamente procedido, é necessário que a empresa tenha um instrumento preciso para colheita dos dados fiscais da empresa e que determine a forma de tributação que será adequada à espécie empresarial. Geralmente se procede através de registros em sistemas online, através dos quais os contadores realizam o arquivamento organizado das contas empresariais, especialmente dos recolhimentos de tributos, evitando-se, desta forma, a repetição de indébito e os pagamentos extras dispensáveis, em decorrência da diminuição do valor antecipado.

Para que haja a organização de dados, é imprescindível que esse projeto seja acolhido pelos colaboradores de toda a empresa, a começar pela própria gestão que, se não aderir fielmente à veracidade da entrega de informações, comprometerá todo o sistema de carga, informação e dedução dos dados referentes aos tributos.

É bastante comum se observar a realização de uma radiografia generalizada da empresa, através da confecção de uma matriz fiscal, documento responsável pelo registro de todas as informações fiscais e tributárias da companhia. Todos os tributos, sejam estes taxas, impostos ou contribuições, não relatados, conferidos e enumerados, com seus valores e sua margem de supressões (descontos) e agravamentos (multas e possíveis correções). Pretendese demonstrar, através deste documento, o quanto cumpre a empresa em pagamentos de tributos, qual a margem de descontos que porventura possa auferir, qual a base de cálculo e quais são as alíquotas dos tributos a serem pagos, tudo através de um comportamento proativo na gestão, analisando-se o quanto já dispendeu em relação às multas sofridas e correções que porventura já tenham ocorrido. 
Research, Society and Development, v. 9, n. 10, e2489108512, 2020

(CC BY 4.0) | ISSN 2525-3409 | DOI: http://dx.doi.org/10.33448/rsd-v9i10.8512

Em seguida, é necessário traçar estratégias em calendários de pagamento. É importante que se tenha em mente que o pagamento antecipado não suscita lucro ao Estado, mas em economia à gestão da empresa. Pode-se fazer a analogia deste calendário com o controle de estoque de produtos perecíveis no supermercado: se não houver organização de prazos, datas, pedidos, entradas e saídas, os produtos passam de sua data de validade e estragam, causando prejuízo ao dono do mercado. Sob essa mesma ótica, tributos não acompanhados pelo analista em datas, prazos, recolhimento, acabam deteriorando as finanças da empresa, causando, por conseguinte, prejuízo à gestão.

Por derradeiro, após a análise dos tributos da empresa, sua correta aferição por datas e valores, especialmente os créditos tributários que sejam passíveis de aferição, é tempo de organizar os dados. Torna-se imprescindível a adoção de um sistema operacional eficiente (e, muitas vezes, bilíngue, trilíngue ou poliglota), capaz de armazenar, de maneira eficiente, todos os dados relacionados às despesas e à receita fiscal, para que a informação ao Fisco seja eficiente, rápida e precisa, reduzindo drasticamente ou, melhor ainda, eliminando a possibilidade de erros, uma vez que o controle sobre suas contas é amplo, automático e irrestrito. É importante que a empresa seja sempre alerta quanto ao seu comportamento na gestão dos documentos e, principalmente, que esteja sempre preparada para ser auditada e fiscalizada, dando provas de sua regularidade fiscal. "O processo de Auditoria tem como finalidade abordar e projetar possíveis soluções para que as imparcialidades sejam excluídas, visando à melhoria nos processos administrativos, financeiros e tributários, como economia fiscal" (Medeiros, 2020).

\subsection{Criminal Compliance como instrumento de prevenção contra corrupção e prática de} Money Laundering

Em sua original concepção, o Compliance teve o escopo de, primordialmente, evitar a disseminação do crime organizado, cuja atuação em empresas - reais e fictas (laranjas) - tem sido sustentáculo de negociações milionárias, geralmente respaldadas em ações revestidas de aparente legalidade, a exemplo de licitações e contratos com o Poder Público. Tal iniciativa, no entanto, tem sido estudada com alguma cautela, tendo em vista o posicionamento de alguns estudiosos, a exemplo de Thomas Rotsch, que acredita que o Compliance pode, também, ensejar a corrupção (Rotsch, 2020).

Com o escopo de combater as práticas ilícitas relacionadas à lavagem de dinheiro e capitais, o GAFI - Grupo de Ação Financeira contra a Lavagem de Dinheiro e o 
Financiamento do Terrorismo, criado em 1989, tem realizado ações voltadas para a prevenção dos referidos crimes, gerando, por conseguinte, um documento de orientação comum a todas as nações. Os Padrões Internacionais de Combate à Lavagem de Dinheiro e ao Financiamento do Terrorismo e da Proliferação, conhecido como as 40 Recomendações do GAFI, são proposições elaboradas de acordo com a experiência de avaliação do grau de corrupção e de técnicas utilizadas no mundo, conforme se observa no sítio eletrônico da organização intergovernamental, reproduzido, em língua Portuguesa, no website da Fazenda Nacional (Brasil, 2020).

Dentre as recomendações, a transparência nas negociações resta livremente ressaltada, porquanto haja, nesse diapasão, uma forte necessidade de se estabelecer uma ligação entre a fonte e o destino de todo recurso financeiro que transita entre pessoas jurídicas, interna e externamente. Com efeito, os crimes de natureza fiscal estão elencados como objeto de larga preocupação do GAFI, uma vez que a evasão fiscal se tornou uma forma fácil de burlar a lei no Brasil. Sem dúvidas, é através do inadimplemento das contas fiscais que a pessoa jurídica, frequentemente e sem qualquer temor à fiscalização, tem buscado integralizar seus haveres, fazendo desta inadimplência uma forma de sustentação financeira da sua empresa, seja através de transações financeiras, seja por negociações internacionais.

Sob uma primeira pauta, o Compliance surgiu como forma de se estabelecer uma normativização interna nas empresas, através de um padrão desenvolvido de condutas éticas e previsão de punições em torno do descumprimento desse regimento administrativo. Surge, desta feita, a figura do administrador regulador, que age proativamente no combate às práticas ilícitas em sua empresa, estabelecendo regras e sanções ao descumprimento de suas normas, com o intuito de fazer-se cumprir, indiretamente, a legislação nacional.

Em um universo onde as negociações podem ser realizadas em uma plataforma digital e em um cenário virtual absolutamente abstrato e distante das regulações fiscais em vários países, torna-se imprescindível, também, problematizar-se acerca de transações com criptomoedas, por exemplo. Tais negociações comportam "alta volatilidade e facilidade de transação", o que pode viabilizar a evasão fiscal. (Bernardes \& Silva, 2020).

Para Cardoso Neto (Cardoso Neto, et al., 2019), em decorrência das dificuldades existentes para localização e análise dessa conduta pelas autoridades, especialmente por haver a prática de crimes-meio ou crimes-fim para a lavagem de capitais, as entidades privadas praticamente se encontram numa posição de prevenção geral ao implementarem programas de Compliance. Isso ocorre porque as empresas agem antes da fiscalização, demonstrando todas as suas movimentações, as estruturas interna e externa de sua empresa, bem como sua vida 
fiscal e financeira, formando uma verdadeira colcha de retalhos com seu histórico, sua atividade, seus colaboradores e toda a sua vida.

\section{Considerações Finais}

Para que haja conformidade das empresas com as leis tributárias, é necessário mais do que o simples comportamento ético e moral de um empreendedor. Isso, no Brasil, tem sido observado porquanto haja, ainda, a necessidade de uma compreensão maior no que se refere aos benefícios auferidos através dos pagamentos de tributos. Existe uma cultura anticumprimento que permeia o cerne de toda questão em torno do contribuinte: os pagamentos de taxas, impostos e contribuições são onerosos, não se vê retorno breve e, pior ainda, as leis que penalizam a evasão fiscal ainda têm cumprimento deferido, dada a inviabilidade de uma fiscalização acurada de todas as milhares de empresas criadas e em funcionamento no país. Não obstante haver-se por prejudicada a fiscalização, em um cenário onde as irregularidades se sobrepõem à capacidade de lotação de fiscais em número e espaço, "as penalidades tributárias, mesmo as de caráter criminal, podem não ser suficientes para inibir comportamento ilegal do contribuinte" (Mendonça \& Filho, 2017).

Para que as leis sejam efetivamente cumpridas, torna-se necessário o planejamento tributário e, mais além, um fiel cumprimento de um plano de Compliance estruturado para a fidelização das atividades da administração tributária, no sentido de permitir maior controle fiscal e menor incidência de episódios de corrupção.

As empresas de grande porte, para efetivar o Compliance, necessitam de uma organização com departamentos voltados para o Planejamento Tributário, mas não apenas isso. É bastante comum a difusão da aplicabilidade do Compliance em outras áreas, como Trabalhista e Financeiro. As adequações financeira, trabalhista, fiscal e tributária tornam-se necessárias para o implemento de exequibilidade das atividades empresariais, de modo a traduzir-se em uma ferramenta imprescindível para a gestão organizacional.

O presente artigo teve por escopo a discussão sobre o Compliance realizado nas empresas, como forma de aprimorar o Planejamento Tributário já realizado, evitando-se, por conseguinte, a evasão fiscal. Mostrou-se, de fato, como um poderoso instrumento de controle tributário, organização fiscal da empresa, com vistas a se revestir - como, de fato, ocorre - em uma vasta proteção contra irregularidades, atos de corrupção e desgoverno da gestão.

É de salutar importância o aprofundamento da pesquisa realizada sobre o Compliance em todas as suas aplicabilidades previstas na seara empresarial. A partir de um estudo 
completo sobre as adequações normativas nas empresas de hoje, as gerações futuras não terão o trabalho de realizar estes ajustes e adequações, mas de pesquisar modelos cada vez mais assertivos e promissores de gestão, o que se traduzirá em economia de tempo e em uma busca de resultados difusos em áreas diversificadas, aprimorando técnicas interdisciplinares, viabilizando modelos inovadores, capacitando melhores gestores. O futuro da pesquisa se encontra na organização normativa, com reflexo difuso nas áreas de atuação das empresas, para um resultado positivo conglobado.

\section{Referências}

Amaral, Y. (2020). Compliance Tributário: importância e implementação. Blog Arquivei. Recuperado de: https://arquivei.com.br/blog/Compliance-tributario-importanciaimplementacao-mf/.

Bernardes, F., \& Silva, S. (2020). Criptomoedas e o Planejamento Tributário. Revista de $\begin{array}{llllll}\text { Direito Tributário } & e & \text { Financeiro, } & 6 & \text { (1), 23-43. }\end{array}$ DOI: http://dx.doi.org/10.26668/IndexLawJournals/2526-0138/2020.v6i1.6451.

Brasil, Fazenda Nacional. Padrões Internacionais de Combate à Lavagem de Dinheiro e ao Financiamento do Terrorismo e da Proliferação. Recuperado de: http://fazenda.gov.br/orgaos/coaf/arquivos/as-recomendacoes-gafi.

Correio 24h. (2020). Justiça determina sequestro de bens de donos da Ricardo Eletro por dívida de R\$ $113 \mathrm{mi}$. Recuperado de: https://www.correio24horas.com.br/noticia/nid/bajustica-determina-sequestro-de-bens-de-donos-da-ricardo-eletro-por-divida-de-r-113-mi/.

Filho, E., Leite, F., \& Martins, J. (2019). Ética Empresarial como base de sustentação do Programa de Compliance: uma breve análise sobre a ética, a integridade e o Compliance. Revista Unicuritiba, 2 (3). DOI: http://dx.doi.org/10.21902/Revrima.v2i26.3891.

Gerhardt, T. \& Silveira, D. (2009). Métodos de Pesquisa. Porto Alegre, Rio Grande do Sul: Editora da UFRGS.

Gil, A. (2008). Métodos e técnicas de Pesquisa Social. São Paulo: Atlas. 
IBPT - Instituto Brasileiro de Planejamento e Tributação. Sonegação Fiscal das empresas. Recuperado de: https://ibpt.com.br/estudos/sonegacao-fiscal-da-empresas/.

Medeiros, B., \& Martins, V. (2020). Produção cientifica relativa à auditoria e Compliance no Brasil: uma análise do período de 2008 a 2018. Revista de la Agrupación Joven Iberoamericana de Contabilidad y Administración de Empresas, 21 (2), 1 - 16. Recuperado de: http://elcriterio.com/revista/contenidos_21_2/Vol21_num2_1.pdf.

Mendonça, M., \& Filho, A. (2017). A indução tributária como meio de construção de uma administração tributária eficiente. Revista Eletrônica do curso de Direito da Universidade Federal de Santa Maria, 12 (3), 816-836. DOI: https://doi.org/10.5902/1981369425690;

Merriam-Webster's Dictionary of Basic English. (2017). USA: Merriam-Webster Inc..

Miyoshi, R., \& Nakao, S. (2012). Riscos de Conformidade Tributária: um estudo de caso no Estado de São Paulo. Revista de Contabilidade e Organizações, 6 (14), 46-76. DOI: https://doi.org/10.11606/rco.v6i14.45400.

Mudrovitsch, R., \& Nóbrega, G. (2020). Compliance público: o controle interno preventivo da probidade na administração. Revista Consultor Jurídico, 2020. Recuperado de: https://www.conjur.com.br/2020-jun-19/improbidade-debate-Compliance-publico-controleinterno-preventivo-probidade-administracao.

Neto, L., Cordeiro, N., Paes, J. (2019). Criminal Compliance antilavagem: prevenção penal por agentes privados e o direito ao silêncio. Revista da Faculdade de Direito UFPR, 64 (2), 89-110. DOI: http://dx.doi.org/10.5380/rfdufpr.v64i2.63741.

Oliveira, E. (2020). Compliance e Lei Anticorrupção. Revista da Faculdade Mineira de Direito - PUC Minas, 23 (45), 367-384.

Pereira A.S. et al. (2018). Metodologia da pesquisa científica. [e-book]. UAB/NTE/UFSM. Recuperado de: https://repositorio.ufsm.br/bitstream/handle/1/15824/Lic_Co mputacao_Metodologia-Pesquisa-Cientifica.pdf?sequence=1. 
Quentin, C. (2019). Acceptable levels of tax risk as a metric of corporate tax responsibility: theory, and a survey of practice. Nordic Tax Journal. Issue 1. Recuperado de: https://content.sciendo.com/view/journals/ntaxj/2019/1/article-p1.xml?language=en.

Rotsch, T. (2020). Corrupção e Criminal Compliance. Revista de Estudos Criminais, 18 (73), 31-51. Recuperado de: http://itecrs.org/edicoes/ano:2019/titulo:v18n73p31-51.

Viol, A. (2015). A administração tributária moderna e a maximização do cumprimento tributário: algumas reflexões sobre o caso brasileiro. Revista da Receita Federal: estudos tributários e aduaneiros, 1 (2). Recuperado de: https://receita.economia.gov.br/publi cacoes/revista-da-receita-federal/revista-vol1-no2-jan_jul_2015.pdf/view.

\section{Porcentagem de contribuição de cada autor no manuscrito}

Walkyria Carvalho - 50\%

José Luiz Alves - 50\% 